\title{
Conjunctival Diphtheria
}

\author{
by
}

SYAHRIR PASARIBU

(From the Department of Child Health, School of Medicine, University of Nortb Sumatera / Dr. Pirngadi Hospital, Medan)

\begin{abstract}
Three cases of conjunctival diphteria in 3 siblings of one family with the ages of 7 months, 6 and 8 years had been reported. These children had never obtained complete DTP immunization, one of them had been once immunized with DIP.

General signs encountered were conjunctival byperemia, ocular secretion and palpebral edema:

$A$ relationship between length of ailment with appearance of clinical symptom and severity of the disease was noted.

Myocarditis as a complication was found in one case. Treatment in this series consisted of intravenous anti diphtheria serum (ADS) and intramuscular procain penicillin.
\end{abstract}




\section{Introduction}

Diphtheria is an acute inflammatory disease preventable by immunization caused by Corynebacterium diphtheria and frequently found in developing countries in cluding Indonesia. The various complications were myocarditis, neuritis and airway obstruction, resulting in nasal and oral bleeding as reported by Saguanchua, Thailand in 1984 [1]. This disease is significantly important in the aspect of preventive endeavours. Various familiar types of diphtheria eg. nasal, tonsillar pharyngeal and laryngeal are commonly found but conjunctival diphtheria is very rare [2].

Clinical signs and symptoms are the main guidelines for diagnostic establishment. Delay in therapy can make the patient at risk [3]. The clinical features of the disease depend on the site of the lesion, but its specific characteristic is the finding of a thin, greyish membrane which easily bleeds on removal. Conjunctival diphtheria is located on the palpebra signified by redness of the palpebra, edema and the presence of a greyish-white membrane [4].

The objective of this report is to evaluate the clinical features of this disease its complications and therapy.

\section{Report of Cases}

\section{Case 1}

$\mathrm{H}$, male, 7 months old, was admitted to our hospital on $12^{\text {th }}$ April 1990 with fever, red eyes and swollen eyelids. The initial sign was fever and 4 days later the eyelids reddened and swoles accompanied with secretion of the eyes. He had been treated with erythromycin and gentamycin eye drops prior to hospitalization. Familial history revealed tha both parents and an elder brother and sister of the patient also suffered from the same disease with similar symptoms The patient had been immunized with DTP $1 x$ and BCG physical.

Diagnostic examination revealed conjunctival hyperemia, palpebral edema and presence of a membrane on the left and right palpebrae inferior which bled on removal. Laboratory findings were within normal limits whilst direct smear and culture were negative. ECG examination confirmed the presence of myocarditis. The patients was then treated with anti diphtheria serum and procain Penicillin. Two days later, the clinical signs disappeared and he was discharged in good health.

\section{Case 2}

W, female, 6 years old, elder sister of case 1, was admilled with red eyes of 5 days duration. Conjunctival hyperemia and eye secretion were encountered. ECG finding and the result of routine blood analysis were within normal limits. Immunization status was negative and so was the result of culture and direct smear of membrane.

The treatment given to this patient was the same as case 1. Two days after treatment, the clinical symptoms vanished and she returned home in good condition.

\section{Case 3}

HO, male, 8 years old, elder brother of case 2, was also admitted with red eycs of 5-day duration. Conjunctival hyperemia, palpebral edema, eye secretion and presence of greyish-white membrane on the left and right palpebrae inferior were evident. Result of routine blood analysis and ECG examination were normal. Two days after being treated with anti-diphtheria serum and procain penicillin, the clinical signs and symploms disappeared and he was discharged in good health.

\section{Discussion}

Three cases of conjunctival diphtheria in relates with the quantity of signs and ocone family where both parents also suffered from the same disease with similar signs and symptoms have been reported. One of the cases was a 7 month-old infant which was a rare accurence of diphtheria that usually strikes children within the age of 2 to 6 years. That the clinical signs and symptoms that were encountered varied from fever to myocarditis as illustrated in the Table I. Clinical signs frequently encountered in our series were conjunctival hyperemia, eye secretion and presence of a greyish-white membrane. The above table illusterates that duration of ailment corcurrence of Cardiac complication Case 1 with a 7-day fever, conjunctival hyperemia, eye secretion, palpebral edema and greyish-white membrane with myocarditis as a complication verified this.

Our treatment consisted of 40.000 IU/intravenous anti diphtheria serum in $200 \mathrm{ml}$ saline solution which has the advantages as follows : (1) peak serum level achieved within 30 minutes after administration; (2) very speedy distribution of antitoxin in the saliva; (3) less frequent complication of myocarditis and neuritis [5]

Table I. Clinical signs, symptoms and laboratory findings

\begin{tabular}{|lccc|}
\hline Signs/symptoms/lab.examination & Case 1 & Case 2 & Case 3 \\
\hline 1. Duration of ailment & 7 days & 5 days & 5 days \\
2. F e v e r & $(+)$ & $(-)$ & $(-)$ \\
3. Conjunctival hyperemia & $(+)$ & $(+)$ & $(+)$ \\
4. Eye secretion & $(+)$ & $(+)$ & $(+)$ \\
5. Palpebral edema & $(+)$ & $(-)$ & $(+)$ \\
6. Greyish-white membrane & $(+)$ & $(-)$ & $(+)$ \\
7. M y o c a r d i t i s & $(+)$ & $(-)$ & $(-)$ \\
8. Routine blood analysis & N & N & N \\
9. Direct smear & $(-)$ & $(-)$ & $(-)$ \\
10. C u l t u r e & $(-)$ & $(-)$ & $(-)$ \\
\hline
\end{tabular}




\section{Conclusion}

Three cases of conjunctival diphtheria in children of 7 months, 6 and 8 years of age have been presented. Early and correct diagnosis and proper and adequate treatment are necessary for the prevention of unwanted complication This report also showed the relationship between duration of ailment and clinical signs with the severity of the disease.

\section{REFERENCES}

1. Saguanchua P, Patamasucon P, Yuthasombop S Hemorrhagic diphtheria. Southeast Asian J Trop Med Pub Hlth. 1984; 15(2): 261-4.

2. Belsey MA. Skin infections and the epidemiology of diphtheria : Acquisition and persistence of Corynebacterium diphtheriae infections. Am J Epidemiol 1975; 102: 197.

3. Vaughan VC, Mc Kay RJ, Berhmann RE. Diphtheria in Nelson textbook of pediatrics; $11^{\text {th }}$ eds., Tokyo: W.B. Saunders Company, Igaku Shoin 1979: 746-52
4. Krugman S, Kalz SL, Gershion $\Lambda \Lambda$, Wilfen $C M$. Diphtheria in infectious diseases of children' $8^{\text {th }}$ ed. St. Louis - Toronto - Princeton: The Mosby Company; 1985: 22-31.

5. Tasman A et al. Importance of intravenous injection of diphtheria anti serum. Lancet 1958; i : 1299. 